\title{
Physical Education Majors' Judgments about Inclusion and Teaching Students with Disabilities
}

\author{
Samuel R. Hodge ${ }^{1} \&$ Gloria Elliott $^{2}$ \\ ${ }^{1}$ Department of Human Sciences, The Ohio State University, USA \\ ${ }^{2}$ Department of Health, Physical Education, Recreation and Human Services, North Carolina Agricultural \& \\ Technical State University, USA \\ Correspondence: Samuel R. Hodge, Ph.D., Professor, The Ohio State University, Department of Human Sciences, \\ A-254 PAES Building, 305 West $17^{\text {th }}$ Avenue, Columbus 43210-1297, Ohio, USA. Tel: 1-614-292-8364. E-mail: \\ hodge.14@osu.edu
}

Received: February 2, 2013 Accepted: February 18, 2013 Available online: March 8, 2013

doi:10.11114/jets.v1i1.88

URL: http://dx.doi.org/10.11114/jets.v1i1.88

\begin{abstract}
The purpose of this study was to analyze the beliefs about inclusion and teaching students with disabilities of physical education (PE) majors from universities in North Carolina (NC). The participants were PE majors ( $n=$ 147) and other enrolled students $(n=30)$ at colleges and universities in NC. The research method was descriptive survey (Fraenkel \& Wallen, 1990) situated in the theory of planned behavior (Ajzen, 2001). A survey was used to collect posttest data, which were analyzed with Kruskal-Wallis ANOVA tests to determine differences as a function of gender, ethnicity, and experience teaching persons with disabilities. The participants did not differ in their beliefs about the concept of inclusion. In contrast, there were differences as a function of gender and ethnicity in acceptance of teaching students with disabilities and perceived need for additional preparation. Implications of this research for professional preparation are discussed.
\end{abstract}

Keywords: beliefs, inclusion, physical education, theory of planned behavior

\section{Introduction}

Globally there is a wealth of research on the beliefs and attitudes of physical education (PE) majors toward teaching children and youth with disabilities (Bartoňova, Kudlaček, \& Bressan, 2007; Folsom-Meek, Nearing, Groteluschen, \& Krampf, 1999; Folsom-Meek, Nearing, \& Kalakian, 2000; Hodge, 1998; Hodge \& Jansma, 1998, 1999; Kowalski \& Rizzo, 1996; Martin \& Kudláček, 2010; Patrick, 1987; Rizzo \& Kirkendall, 1995; Rizzo \& Vispoel, 1992; Rowe \& Stutts, 1987; Stewart, 1990). Collectively findings in this area of research indicate that PE majors' attitudes tend to change in a favorable direction as a function of matriculation in adapted physical education (APE) courses and direct contacts or experiences in teaching or interacting with individuals with disabilities.

Folsom-Meek et al. (1999), for example in a study of PE majors $(n=2,943)$ at 192 colleges and universities across the United States (US), affirmed main effects for (a) gender (favoring females), (b) academic major (favoring non-PE majors), and (c) hands-on experience (favoring experience teaching individuals with disabilities) in positively influencing participants' attitudes toward teaching students with disabilities. There are inconsistencies however in research findings from studies on the attitudes of female versus male PE majors toward teaching students with disabilities. Compared to males, typically female PE majors express more favorable attitudes toward teaching individuals with disabilities (Folsom-Meek et al., 1999). Important though after controlling for experience differences using an analysis of covariance statistical application, Hodge and Jansma (1999) found no significant differences between the attitudes of male and female PE majors.

There are also inconsistencies in findings across studies on the attitudes of PE majors with previous experience versus those with little or no experience teaching or interacting with individuals with disabilities (Folsom-Meek et al., 1999; Hodge \& Jansma, 1999). Compared to those with less or no experience, typically PE majors with experience express more favorable attitudes toward teaching individuals with disabilities. Kowalski and Rizzo (1996) asserted that APE course work and experience in teaching or working with individuals with disabilities influences PE majors' attitudes indirectly through perceived competence. Further they asserted that PE majors' 
perceived competence in teaching or working with individuals with disabilities is a strong predictor of favorable attitudes. It appears that additional research is needed to examine the attitudes of PE majors in association with gender, their experiences, and other potentially salient variables (Kozub \& Lienert, 2003).

On the one hand, much of the research examining the attitudes of PE majors has been conducted at predominantly White institutions of higher education (Folsom-Meek et al., 1999; Hodge \& Jansma, 1999; Kowalski \& Rizzo, 1996). On the other hand there is a void of research focused on the attitudes of PE majors at minority-serving colleges and universities. Moreover few researchers have examined PE majors' attitudes as a function of their ethnicity or race. An exception to this is Hodge and Jansma's (1999) national survey of 474 physical education majors. The sample was comprised of $292(62 \%)$ males and $182(38 \%)$ females. Of these, 52 respondents (11\%) indicated that they were ethnic minorities such as African Americans (35 males 7.4\% and 17 females 3.6\%); whereas, 421 respondents (88.8\%) indicated they were Whites, non-Hispanic (257 males 54.2\% and $16434.6 \%$ ). Statistical analysis indicated that these respondents were not significantly different on attitude scores as a function of their ethnic status. Notwithstanding Hodge and Jansma's study, this line of attitudinal research is undeveloped, particularly at minority-serving institutions of higher education.

Minority-serving institutions include American Indian-serving colleges and universities, Tribal Colleges and Universities (TCUs), Hispanic-serving institutions, and Historically Black Colleges and Universities (HBCUs). The Department of Education identifies minority-serving colleges and universities based on either one of two criteria: (a) legal standing or (b) percentage enrollment of ethnic minority students. That is African American/Black, American Indian/Alaska Native, Asian/Pacific Islander, or Hispanic students (Li, 2007). The first criterion means that both HBCUs and TCUs including some American Indian-serving institutions are defined by law. These institutions cannot increase in number unless the US Congress acts to designate additional institutions as HBCUs or TCUs ( $\mathrm{Li}, 2007)$. The second criterion is where institutions are defined as minority-serving institutions if they have a significant enrollment of a specific minority group (typically at least $25 \%$ ), but do not have legal status as an HBCU or TCU. The University of North Carolina at Pembroke and Fayetteville State University are such historic places located in the southeastern region of North Carolina, as examples.

The University of North Carolina at Pembroke (UNCP) is an American Indian-serving institution. It was established with a fundamental mission of educating American Indian students. American Indian-serving colleges and universities are defined as TCUs or institutions of higher education that are not HBCUs or TCUs, but where American Indian/Alaska Native students comprise at least $25 \%$ of the total undergraduate (UG) enrollment, while students in each of the other minority groups comprise less than $25 \%$ of the total UG enrollment (Li, 2007). Today, however, African American/Black students nearly double the number American Indian students at UNCP. In fall 2010, there were 1980 African American/Black (32.1\%) UG students compared to 999 American Indian/Alaskan Native (16.2\%) UG students enrolled at the university (UNCP, 2011). UNCP offers bachelor's degrees in the Department of Health, Physical Education and Recreation leading to K-12 health and physical education teacher certification (UNCP, 2011).

The Higher Education Act of 1965 define HBCUs as institutions of higher education established before 1964 whose foremost mission was then, and largely remains today, the education of Black Americans (Wilson, 2008). Fayetteville State University (FSU) is a HBCU and stands proudly as a public comprehensive regional university and constituent member of the University of North Carolina (UNC) system. FSU offers bachelor's degrees in the Department of Health, Physical Education and Human Services leading to health and physical education teacher certification. In fall 2010, there were 4,018 African American/Black (70\%) students followed by 955 White (17\%), 241 Hispanic (4\%), 79 American Indian/Alaskan Native (1\%), and 60 Asian (1\%) students enrolled at the university (FSU, 2011).

Determining and analyzing the beliefs of PE majors is important in the preparation of these future teachers. The purpose of this study was to analyze the beliefs about inclusion and teaching students with disabilities of PE majors and students with other academic majors at universities in the State of NC. The study is unique in that rarely have the beliefs of PE majors at minority-serving institutions been analyzed in regards to inclusion and teaching students with disabilities in physical education.

\section{Theoretical Framework}

The theory of planned behavior $(\mathrm{TpB})$ is used to situate this study for interpreting the beliefs of PE majors and other collegians about teaching students with disabilities. In $\mathrm{TpB}$, it is believed that attitudes toward behavior, subjective norms, and perceived behavioral control are the base aggregates of behavioral intention (Ajzen, 2001). $\mathrm{TpB}$ has three conceptually independent determinants of intention: (a) attitude toward the behaviour which is the 
degree to which a person has a favorable or unfavorable evaluation or appraisal of the behaviour in question; (b) subjective norm which is the perceived social pressure to perform or not perform the behavior; and (c) perceived behavioural control which is the perceived ease or difficulty of performing the behaviour. The foundation of the determinants of intention are three accessible belief systems: (a) behavioral beliefs which influence attitudes toward the behavior, (b) normative beliefs which constitute the underlying determinants of subjective norms, and (c) control beliefs which provide the basis for perceptions of behavioral control (Ajzen, 2001). $\mathrm{TpB}$ was used in the current study to interpret and generalize the findings. Beliefs were operationally defined as accessible beliefs held by college students about inclusion and teaching students with disabilities based on their knowledge, new learning, and experiences (or lack of) teaching individuals with disabilities.

\section{Method}

\subsection{Study Design}

The research method was descriptive survey and the participants were sampled from intact groups, often called convenience sampling (Thomas \& Nelson, 2001). Participants were PE teaching majors $(n=147)$ and other students $(n=30)$ who agreed to participate in the study and had completed APE course work and practicum experiences. The study was approved by the researcher's Institutional Review Board, and each participant signed an informed consent form.

\subsection{Participants and Sampling}

Participants were a cross section of physical education majors $(n=147)$ and other enrolled students $(n=30)$ at an American Indian-serving university, three public HBCUs and four predominantly White universities in North Carolina (NC). The other enrolled students included those with academic majors in biology, childhood education, ethnic studies, exercise science, health education, sociology, and therapeutic recreation. The sampling of participants involved contacting the APE course instructor at each university under study to seek her or his willingness to collect data from students enrolled in APE courses. APE instructors from seven universities agreed, and collected data from students who had varied personal backgrounds, academic majors, and experiences teaching. Due to small returns from Asian/Pacific American $(n=1)$, Hispanic $(n=3)$, and Native American $(n=1)$ respondents, a decision was made to omit these cases. This resulted in 177 usable data sets from Black $(n=98)$ and White $(n=79)$ participants. Table 1 shows gender proportions of female $(n=66,37 \%)$ and male $(n=111,62.7 \%)$ respondents. The sample ranged in age from 18 to 56 years with a mean value of 23.8 years $(S D=6.2)$. Gender and ethnic group differences in age were not found in the sample $(p>.05)$.

\section{Measures}

Data were collected with the Physical Educators' Judgments about Inclusion (PEJI) survey and an accompanying demographic sheet (Hodge, Murata, \& Kozub, 2002). Demographic data included the participants' gender, age, ethnicity or race, academic major, coursework in APE and special education, and experience teaching individuals with disabilities. As designed, the PEJI survey was used to gather data on participants' judgments about inclusion and teaching students with disabilities in PE. Conceptually, judgments represent the cognitive expressions of attitudes (Ajzen \& Fishbein, 2000) and inclusion was defined as instruction of students with and without disabilities together in PE classes. The PEJI is a reliable and valid measure of college students' judgments on (a) inclusion v. exclusion, (b) acceptance of teaching students with disabilities, and (c) perceived training needs, as confirmed from psychometric analyses (Hodge et al., 2002).

In this study, the PEJI was administered with an attached cover sheet that contained general instructions for completing the survey and a definition of inclusion. A definition sheet defining the various disability types appearing in the PEJI also accompanied the survey. Responses on the PEJI were averaged based on its 5-point scoring scale of strongly disagree $=1$ to strongly agree $=5$. Scoring on negatively phrased items was reversed.

\section{Data Collection and Analysis}

At end of the academic semester, the course instructor at each university administered the PEJI survey in class to enrolled students, who were informed that confidentiality would be maintained and that all data would be coded and reported in aggregate form. The independent variable (treatment) was instruction in the introductory APE courses coupled with practicum experiences. Data were collected after the participants had received instruction in an APE course. The dependent variables were PEJI subscale scores.

Descriptive statistics were used to analyze the demographic and PEJI data. Because several research design limitations existed (i.e., use of intact nonrandomized groups and small unequal sample sizes), all assumptions underlying parametric tests could not be satisfied (Thomas \& Nelson, 2001). For those reasons we used a nonparametric alternative, Kruskal-Wallis analysis of variance (ANOVA). The Kruskal-Wallis test is used for 
analyzing data from two or more independent samples and each with at least six cases (Shavelson, 1988). The Kruskal-Wallis test requires only ordinal level data, assumes an underlying continuous distribution, and is computed with an $\underline{H}$ statistic (Levin, 1983; Thomas \& Nelson, 2001).

Kruskal-Wallis tests were used on PEJI's three subscale scores to check for group differences on (a) participants' gender, (b) ethnicity or race, and (c) past experience teaching individuals with disabilities. Because conducting multiple one-way ANOVA tests raises the probability of a Type I error, Bonferroni adjustment was used. The Bonferroni adjustment was achieved by dividing the single test alpha by the number of tests to be performed (Vincent, 1995). In this study, the adjusted alpha level was set at .016 (alpha $=.05$ divided by number of comparisons $=3$ ) for determining group differences as a function of gender specific to responses on each of the three dimensions of the PEJI survey. Likewise the adjusted alpha level was also set at .016 for determining group differences as a function of ethnicity or race for responses on each of the three dimensions of the survey posttest scores. The adjusted alpha level was also set at .016 for determining group differences as a function of past experiences specific to responses on each of the three dimensions of the survey on posttest scores.

\section{Results}

Table 1 presents demographic data from $111(63 \%)$ male and 66 (37\%) female participants. The 177 participants were Black $(n=98,55.4 \%)$ and White $(n=79,44.6 \%)$ undergraduate students in physical education $(n=147$, $83 \%)$ and other $(n=30,17 \%)$ majors. Further, $105(59 \%)$ participants (64 males, 41 females) had past experiences teaching individuals with disabilities, while 72 (41\%) participants (25 females and 47 males) had no such experiences.

Table 1. Descriptive Data on PEJI Subscales for Selected Independent Variables

\begin{tabular}{|c|c|c|c|c|c|c|c|c|c|c|c|}
\hline \multirow[t]{2}{*}{ Variables } & \multirow[t]{2}{*}{$n$} & \multirow[t]{2}{*}{$\%$} & \multicolumn{3}{|c|}{ Subscale $^{1}$} & \multicolumn{3}{|c|}{ Subscale $^{2}$} & \multicolumn{3}{|c|}{ Subscale $^{3}$} \\
\hline & & & $M$ & $M d n$ & $S D$ & $M$ & $M d n$ & $S D$ & $M$ & $M d n$ & $S D$ \\
\hline \multicolumn{12}{|l|}{ Gender } \\
\hline Male & 111 & $63 \%$ & 2.6 & 2.0 & 0.6 & 3.9 & 4.0 & 0.8 & 4.1 & 4.0 & 0.6 \\
\hline Female & 66 & $37 \%$ & 2.8 & 2.0 & 0.5 & 4.0 & 4.0 & 0.6 & 4.3 & 4.5 & 0.7 \\
\hline \multicolumn{12}{|l|}{ Ethnicity/Race } \\
\hline Black & 98 & $55 \%$ & 2.6 & 2.0 & 0.6 & 3.7 & 4.0 & 0.8 & 4.1 & 4.0 & 0.7 \\
\hline White & 79 & $45 \%$ & 2.8 & 2.0 & 0.6 & 4.2 & 4.0 & 0.7 & 4.4 & 4.5 & 0.5 \\
\hline \multicolumn{12}{|l|}{ Academic major } \\
\hline PETE & 147 & $83 \%$ & 2.7 & 2.0 & 0.6 & 4.0 & 4.0 & 0.7 & 4.2 & 4.0 & 0.6 \\
\hline Other majors & 30 & $17 \%$ & 2.8 & 2.5 & 0.6 & 3.7 & 4.0 & 1.0 & 4.1 & 4.0 & 0.9 \\
\hline \multicolumn{12}{|l|}{ Past experience } \\
\hline Yes & 105 & $59 \%$ & 2.7 & 2.0 & 0.6 & 4.0 & 4.0 & 0.8 & 4.3 & 4.5 & 0.6 \\
\hline No experiences & 72 & $41 \%$ & 2.7 & 2.0 & 0.5 & 3.8 & 4.0 & 0.7 & 4.0 & 4.0 & 0.7 \\
\hline
\end{tabular}

Note. Strongly disagree $=1 ;$ Disagree $=2 ;$ Undecided $=3 ;$ Agree $=4 ;$ Strongly agree $=5$.

Note. Subscale ${ }^{1}=$ Subscale 1 (Inclusion v. Exclusion); Subscale ${ }^{2}=$ Subscale 2 (Acceptance Teaching Students with Disabilities); Subscale ${ }^{3}=$ Subscale 3 (Perceived Training Needs).

A series of Kruskal-Wallis ANOVA tests were used to check for group differences as a function of the participants' gender, ethnicity, and past experience on median $(M d n)$ scores for each of the three hypothesized dimensions; that is, subscales of the PEJI survey.

More specifically, a single-factor Kruskal-Wallis test on Subscale 1, Judgments about Inclusion versus Exclusion, revealed that the male and female participants, $H(1,177)=3.86, p=.049$, were not significantly different in their beliefs (judgments) about the concept of inclusion at the conservative .016 alpha level. Both the female and male participants were unsure or tended to disagree with the ideology of inclusion. On the second subscale, Judgments about Acceptance of Students with Disabilities, test result was non-significant, $H(1,177)=0.04, p$ $=.83$, where the female and male participants' median scores of 4.0 respectively showed agreement on this dimension. For Subscale 3, Judgments about Perceived Training Needs, test result was statistically significant, $H$ $(1,177)=7.15, p=.007$, where the female participants perceived a greater need for additional professional 
preparation than their male peers on this dimension.

A separate Kruskal-Wallis test indicated that the PETE majors were not significantly different $[H(1,177)=3.01$, $p=.08]$ in their median scores for items representing the first dimension, Judgments about Inclusion versus Exclusion of the survey, as a function of ethnic status. Both the Black and White participants $(M d n=2.0)$ tended to disagree with the concept of inclusion. On Subscale 2, test result was statistically significant, $H(1,177)=$ $18.45, p=.000$, as the White participants' median scores revealed a higher level of readiness to accept teaching students with disabilities more so than their Black peers' scores. Likewise on Subscale 3, test result was statistically significant, $H(1,177)=8.27, p=.004$, where the White participants perceived a greater need for additional professional preparation than their Black peers.

Lastly, a Kruskal-Wallis test revealed that the PETE majors were not significantly different $[H(1,177)=0.19, p$ $=.66]$ in their median scores for items representing Judgments about Inclusion versus Exclusion as a function of past experience teaching individuals with disabilities. Both participants with and without past teaching experiences $(M d n=2.0)$ tended to disagree with the concept of inclusion. On Subscale 2, the test result was significant, $H(1,177)=6.82, p=.00$, as the participants with prior teaching experiences were more ready to accept teaching students with disabilities than peers with no such experiences. On Subscale 3, test result was significant, $H(1,177)=10.53, p=.001$, where the participants who had past experience teaching perceived a greater need for more and better preparation than their peers with no such experiences.

\section{Discussion and Implications}

In this study, we analyzed the beliefs about inclusion and teaching students with disabilities of PE majors and other enrolled students from colleges and universities in NC. The findings indicate that the female and male participants tended to disagree with full inclusion. In contrast, both male and female participants were accepting of teaching students with disabilities. However the female participants perceived a greater need for additional professional preparation than their male peers. In terms of group differences based on ethnic status or race, the White participants expressed a higher level of readiness to accept teaching students with disabilities and they perceived a greater need for additional professional preparation than the Black collegians. Similarly, those with prior teaching experiences were more ready to accept teaching students with disabilities than those participants with no such experiences. What's more, the participants who had prior experience teaching individuals with disabilities perceived a greater need for more and better professional preparation than those with no prior experiences. It is interesting to note that most participants believed they needed more and better training to acquire knowledge and skills before feeling confident teaching students with disabilities. Plausibly, although they believed teaching students with disabilities was socially responsible (normative belief), their perceived limited behavioral control (control beliefs) to do so effectively was a result of their perceived inadequate training, which would in-turn have a negative impact on their willingness to accept the inclusion of students with disabilities in their PE classes.

The logic of $\mathrm{TpB}$ posits that intentions to teach students with disabilities in PE contexts, together with strength of perceived behavioral control, predict the likelihood that a teacher will include such students in class activities. In this logic, PE majors' intentions to teach students with disabilities are determined by their attitudes toward teaching such students and by perceived social pressure to do so (subjective norm). Further, their intentions are influenced by perceived control over requisite teaching behaviors such as skill in managing behaviors and individualizing instruction (e.g., adapting lesson plans and modifying activities). Given adequate control over such teaching behaviors, future teachers are likely to carry out their intentions to teach students with disabilities who are included in their classes. Then again challenges such as managing student behaviors and insufficient preparation on how best to individualize instruction may hinder a teacher's sense of control to effectively include students with disabilities in class activities. In $\mathrm{TpB}$, such challenging conditions would have an undesirable influence on a PE teacher's control beliefs and self-efficacy in teaching students with disabilities (Hodge et al., 2009).

Consistently, previous studies confirm that matriculation in introductory APE courses with practicum experiences promotes favorable attitude shifts for teaching students with disabilities (Hodge \& Jansma, 1999). Exposure to children and youths with disabilities tends to affect PE majors' beliefs favorably about teaching such children and youth. Still, there is a need for more and better preparation of PE majors. In TpB, for instance, the study of specialized APE content and pedagogical knowledge during professional preparation coupled with practicum experiences is requisite to them becoming more accepting of teaching children and youths with disabilities. Educators must consider such factors when making decisions on changes to PETE curricular. 


\section{References}

Ajzen, I. (2001). Nature and operation of attitudes. Annual Review of Psychology, 52, 27-58.

Ajzen, I., \& Fishbein, M. (2000). Attitudes and the attitude-behavior relation: Reasoned and automatic processes. In W. Stroebe \& M. Hewstone (Eds.), European Review of Social Psychology (pp. 1-33). New York, NY: John Wiley \& Sons.

Bartoňova, R., Kudlaček, M., \& Bressan, L. (2007). Attitudes of future physical educators toward teaching children with disabilities in physical education in the Republic of South Africa. Acta Universitatis Palackianae Olomucensis, Gymnica, 37(4), 69-75.

Fayetteville State University. (2011). Student enrollment - Fast facts. Retrieved from http://www.uncfsu.edu/ir/student_enrollment.htm.

Folsom-Meek, S. L., Nearing, R. J., Groteluschen, W., \& Krampf, H. (1999). Effects of academic major, gender, and hands-on experience on attitudes of preservice teachers. Adapted Physical Activity Quarterly, 16, 389-402.

Folsom-Meek, S. L., Nearing, R. J., \& Kalakian, L. H. (2000). Effects of an adapted physical education course in changing attitudes. Clinical Kinesiology, 54(3), 52-58.

Fraenkel, J. R., \& Wallen, N. E. (1990). How to design and evaluate research in education. San Francisco, CA: McGraw-Hill.

Hodge, S. R. (1998). Prospective physical education teachers' attitudes toward teaching students with disabilities. Physical Educator, 55(2), 68-77.

Hodge, S. R., Ammah, J. O. A., Casebolt, K. M., LaMaster, K., Hersman, B. L., Samalot-Rivera, A., \& Sato, T. (2009). A diversity of voices: Physical education teachers' beliefs on teaching students with disabilities. International Journal of Disability, Development and Education, 56(4), 401-419.

Hodge, S. R., \& Jansma, P. (1998). Attitude change of physical education majors toward teaching students with varied disability types. Clinical Kinesiology, 51(4), 72-79.

Hodge, S. R., \& Jansma, P. (1999). Effects of contact time and location of practicum experiences on attitudes of physical education majors. Adapted Physical Activity Quarterly, 16, 48-63.

Hodge, S. R., Murata, N. M., \& Kozub, F. (2002). Physical educators' judgments about inclusion: A new instrument for pre-service teachers. Adapted Physical Activity Quarterly, 19, 435-452.

Kowalski, E. M., \& Rizzo, T. L. (1996). Factors influencing preservice student attitudes toward individuals with disabilities. Adapted Physical Activity Quarterly, 13, 180-196.

Kozub, F. M., \& Lienert, C. (2003). Attitudes toward teaching children with disabilities: Review of literature and research paradigm. Adapted Physical Activity Quarterly, 20(4), 323-346.

Levin, J. (1983). Elementary statistics in social research ( $3^{\text {rd }}$ ed.). New York, NY: Harper \& Row.

$\mathrm{Li}, \mathrm{X}$. (2007). Characteristics of minority-serving institutions and minority undergraduates enrolled in these institutions (NCES 2008-156). National Center for Education Statistics, Institute of Education Sciences, U.S. Department of Education. Washington, DC.

Martin, K., \& Kudláček, M. (2010). Attitudes of pre-service teachers in an Australian university towards inclusion of students with physical disabilities in general physical education programs. European Journal of Adapted Physical Activity, 3(1), 30-48.

Patrick, G., D. (1987). Improving attitudes toward disabled persons. Adapted Physical Activity Quarterly, 4, 316-325.

Rizzo, T. L., \& Kirkendall, D. R. (1995). Teaching students with mild disabilities: What affects attitudes of future physical educators? Adapted Physical Activity Quarterly, 12, 205-216.

Rizzo, T. L., \& Vispoel, W. P. (1992). Changing attitudes about teaching students with handicaps. Adapted Physical Activity Quarterly, 9, 54-63.

Rowe, J., \& Stutts, R. M. (1987). Effects of practica type, experience, and gender on attitudes of undergraduate physical education majors toward disabled persons. Adapted Physical Activity Quarterly, 4, 268-277.

Shavelson, R. J. (1988). Statistical reasoning for the behavioral sciences $\left(2^{\text {nd }}\right.$ ed.). Needham Heights, MA: Allyn and Bacon. 
Stewart, C. C. (1990). Effect of practica types in preservice adapted physical education curriculum on attitudes toward disabled populations. Journal of Teaching in Physical Education, 10, 76-83.

Thomas, J. R., \& Nelson, J. K. (2001). Research methods in physical activity (4 ${ }^{\text {th }}$ ed.). Champaign, IL: Human Kinetics.

University of North Carolina at Pembroke. (2011). About UNCP. Retrieved from http://www.uncp.edu/.

Vincent, W. J. (1995). Statistics in kinesiology. Champaign, IL: Human Kinetics.

Wilson, V. R. (2008). The effect of attending an HBCU on persistence and graduation outcomes of African-American college students. In C. L. Betsey (Ed.), Historically black colleges and universities (pp. 5-47). New Burnswick, NJ: Transaction Publishers.

\section{(c) $)$ EY}

This work is licensed under a Creative Commons Attribution 3.0 License. 